BMJ Open Diabetes

Research

\& Care

\section{Response evaluation of SGLT2 inhibitor therapy in patients with type 2 diabetes mellitus using ${ }^{18}$ F-FDG PET/MRI}

To cite: Rasul S, Geist BK, Brath $\mathrm{H}$, et al. Response evaluation of SGLT2 inhibitor therapy in patients with type 2 diabetes mellitus using ${ }^{18} \mathrm{~F}-\mathrm{FDG}$ PET/MRI. BMJ Open Diab Res Care 2020;8:e001135. doi:10.1136/ bmjdrc-2019-001135

Received 19 December 2019 Revised 12 February 2020 Accepted 14 February 2020
Check for updates

C Author(s) (or their employer(s)) 2020. Re-use permitted under CC BY-NC. No commercial re-use. See rights and permissions. Published by BMJ.

For numbered affiliations see end of article.

Correspondence to Dr Barbara Katharina Geist; barbara.geist@meduniwien. ac.at

\section{ABSTRACT}

Introduction Inhibitors of sodium-glucose linked transporter-2 (SGLT2i) are enhancing glucose excretion in the proximal renal tubules, and thus are increasingly used to lower blood glucose levels in patients with type 2 diabetes mellitus (T2DM). The glucose analog 2-deoxy-2$\left({ }^{18} \mathrm{~F}\right)$ fluoro-D-glucose (FDG) can be used to quantify renal function in vivo, and due to an affinity for SGLT2 could also provide information about SGLT2 transporter function. Our objectives in this study were, therefore, to assess the impact of SGLT2i on renal function parameters in patients with T2DM and identify predictive parameters of long-term response to SGLT2i using dynamic FDG positron emission tomography (PET)/MRI.

Methods PET FDG renal function measures such as mean transit time (MTT) and general renal performance (GRP) together with glomerular filtration rate (GFR) were determined in 20 patients with T2DM before (T2DM and 2 weeks after initiation of therapy with SGLT2i $\left(\mathrm{T}_{2} \mathrm{DM}_{\text {SGLT2 })}\right)$. Additionally, dynamic FDG PET data of 24 healthy subjects were used as controls.

Results MTT in T2DM in healthy controls ( $5.7 \mathrm{~min}$ vs $4.3 \mathrm{~min}, \mathrm{p}=0.012$ ) and significantly decreased to $4.4 \mathrm{~min}$ in $\mathrm{T}_{2} \mathrm{DM}_{\mathrm{SGLT2}}(\mathrm{p}=0.004)$. GRP of T2DM SGLT2i $_{\text {was higher than of T2DM }}$ baseline $(5.2$ vs $4.7, \mathrm{p}=0.02$ ) and higher but not significantly than of healthy individuals ( 5.2 vs $5.1, p=0.34$ ). Expectedly, GFR of healthy participants was significantly higher than

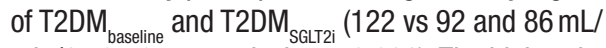
$\mathrm{min} / 1.73 \mathrm{~m}^{2}$, respectively; $\left.p<0.001\right)$. The higher the GRP value in kidneys of T2DM $\mathrm{SG}_{\mathrm{SGT} \text {; }}$, the lower was the glycated hemoglobin level 3 months after therapy initiation.

Conclusion MTT and GRP values of patients with T2DM shifted significantly toward values of healthy control 2 weeks after therapy with SGLT2i begins. GRP in $\mathrm{T} 2 \mathrm{DM}_{\text {SGLT2i }}$ was associated with better long-term glycemic response 3 months after initiation of therapy. Trial registration number NCT03557138.

\section{INTRODUCTION}

Glucose transporters (GLUTs) and sodiumdependent glucose cotransporters, also known as sodium-glucose linked transporters (SGLTs), are mediators for glucose transportation and play prominent roles in cellular glucose uptake, homeostasis and metabolism.

\section{Significance of this study}

What is already known about this subject?

- Inhibitors of sodium-glucose linked transporter-2 (SGLT2i) are used to lower blood glucose levels in patients with type 2 diabetes mellitus.

What are the new findings?

- The glucose analog 2-deoxy-2-( $\left.{ }^{18} \mathrm{~F}\right)$ fluoro-Dglucose (FDG) can provide information about SGLT2 transporter function most probably due to its affinity for SGLT2.

- We could show that FDG renal function measures among patients with type 2 diabetes mellitus altered significantly toward values of healthy control 2 weeks after therapy begins with SGLT2i, which confirms the renoprotective effects of SGLT2i therapy.

How might these results change the focus of research or clinical practice?

- Renal function improved due to SGLT2i therapy after 2 weeks of therapy.

- FDG renal function parameters were able to predict long-term glycemic response 3 months after initiation of SGLT2i therapy.

While GLUTs mediate the glucose uptake in the brain, heart and liver, SGLTs are primarily responsible for glucose transport in the kidney. ${ }^{1}$ Inhibition of the protein SGLT2 is the key mechanism of action of gliflozin drugs that are used as oral antidiabetic therapy in patients with type 2 diabetes mellitus (T2DM), the most common type of diabetes.

SGLT2s are mainly expressed in the proximal tubule segments of the nephron and are responsible for the reabsorption of more than $90 \%$ of the filtered glucose that normally takes place in glomerular capillary membranes. ${ }^{2}$ Expression of SGLT2 proteins in renal proximal tubules is positively correlated with the levels of blood glucose and is significantly higher in patients with diabetes than in healthy individuals. ${ }^{3}$ Via hindrance of glucose 
reabsorption, SGLT2 inhibitors (SGLT2i) increase the rate of glucose excretion in the proximal renal tubules and subsequently induce glucosuria and reduce blood glucose level. Aside from the fact that the therapy might be associated with some adverse effects such as urinary tract infection, pollakisuria or ketoacidosis, numerous studies could demonstrate improvement of insulin resistance and glycemic control with reduction of glycated hemoglobin (HbA1c) levels, body weight and blood pressure values in patients with T2DM treated with SGLT2i. ${ }^{4-8}$ Furthermore, according to observations of previous studies, SGLT2i, additionally, can safely be applied to patients with diabetes having mild to moderate chronic kidney diseases ${ }^{9}$ and offer renoprotective effects such as improvement of glomerular filtration rate (GFR) and albuminuria for these patients. ${ }^{1011}$

The glucose analog 2-deoxy-2- $\left({ }^{18} \mathrm{~F}\right)$ fluoro-D-glucose (FDG) is the most frequently routinely used radiopharmaceutical for positron emission tomography (PET), particularly to detect tumorous cells and inflammatory tissues. Indeed, FDG reaches organs via different GLUTs, whereby GLUT-2 is responsible for the glucose uptake in the kidneys. ${ }^{1}$ Although several reports from previous studies revealed no reabsorption of FDG in the proximal tubules of the kidney, ${ }^{12}{ }^{13}$ some experimental studies demonstrated slight SGLT2 affinity for FDG and showed that under normal conditions about 10\% of FDG was reabsorbed in the proximal tubule. ${ }^{14}$ A major fraction of the tracer, however, is excreted via glomerular filtration through the kidneys, which enables the reliable estimation of various renal functional parameters including GFR and outflow efficiency. ${ }^{15}$ Based on these observations, we conducted a prospective clinical trial to analyze the effects of SGLT2i treatment on both renal function and glucose utilization in patients with T2DM and healthy individuals using dynamic FDG PET/MRI scans. One of the renal function parameters that are frequently used in nuclear medicine is the mean transit time (MTT), which is the averaged travel time of a tracer through a certain tissue and is used to quantify absolute renal function as well as renal outflow. ${ }^{16}$ Furthermore, the renal tracer uptake within the first minutes of tracer injection is used to quantify the general renal performance (GRP), a parameter that is generally used to determine differential renal function or GFR. ${ }^{17}$ We hypothesized that FDG renal parameters such as MTT, outflow efficacy and GRP measured at baseline $\left(\mathrm{T}_{2} \mathrm{DM}_{\text {baseline }}\right)$ and 2 weeks after initiation of gliflozin therapy $\left(\mathrm{T}_{2} \mathrm{D} \mathrm{M}_{\mathrm{SGLT2i}}\right)$ could be used to indicate a patient's response 3 months after initiation of SGLT2i therapy.

\section{STUDY DESIGN AND METHODS Patients}

Twenty consecutive patients with T2DM (10 men and 10 women, aged $65 \pm 10$ years (range $38-78)$ ) with a mean HbAlc of $7.5 \%$ ( $58 \mathrm{mmol} / \mathrm{mol}) \pm 0.9$ (range 6.6 (49)-9.8 (84) ) and a mean interval from first diagnosis of diabetes of 12 years (range 1-30) were included in this prospective clinical trial. All patients underwent two dynamic FDG PET/MRI examinations: one before and the other 2 weeks after initiation of SGLT2i therapies.

A written informed consent was provided by every studied patient prior to study participation. Inclusion criteria were T2DM, age between 20 and 74 years, HbA1c level $>6.2 \%$, planned initiation with SGLT2i treatment and intact renal function (serum creatinine $<1.5 \mathrm{mg}$ / $\mathrm{dL}$ or urinary albumin to creatinine ratio $<300 \mathrm{mg} / \mathrm{g}$ in a random urine sample). Exclusion criteria were anatomically altered or harmed kidneys, corticosteroids and diuretic therapies, MRI unsafe implants such as pacemakers and implantable cardioverter-defibrillators, previously not tolerated MRI contrast agents, claustrophobia, not able to lie still without changing position for a minimum of $30 \mathrm{~min}$, and pregnancy.

Twenty-four healthy individuals (18 men, 6 women), with a mean age of $39 \pm 9$ (range 21-65 years), scanned with the same FDG PET/MRI protocol, served as a control group.

\section{SGLT2i therapy and follow-up}

The clinical indication for SGLT2i therapies was independent of the onset of T2DM and was recommended by experienced diabetologists based on the current international guidelines ${ }^{18}$ as monotherapy or in combination with other antidiabetic medications, including insulin the day after the baseline PET/MRI scan. Of the 20 patients, $16(80 \%)$ were treated with $10 \mathrm{mg}$ daily dose of empagliflozin (Jardiance) and 4 patients with $10 \mathrm{mg}$ daily dose of dapagliflozin (Forxiga).

Therapy response was documented 3 months after initiation of SGLT2i therapy by determination of HbAlc serum levels. According to the reduction of HbAlc level in relation to baseline, we divided patients into two groups: responder with any reduction of the original $\mathrm{HbA1c}$ value and non-responder with no change or increase of HbA1c.

\section{FDG positron emission tomography/MRI}

After obtaining fasting blood samples to determine metabolic and chemical laboratory parameters (blood lipids, renal and kidney functions) and after an intravenous hydration with $500 \mathrm{~mL} 0.9 \% \mathrm{NaCl}$ (normal saline), participants were asked to empty their bladder directly before injection of $3 \mathrm{MBq} / \mathrm{kg}$ body weight of ${ }^{18} \mathrm{~F}$-FDG. PET acquisition (Siemens Biograph mMR, Siemens Healthcare Diagnostics, Germany) started immediately after tracer injection and continued for $30 \mathrm{~min}$. The field of view covered the abdomen, including the kidneys and the abdominal aorta. PET list-mode data were reconstructed into a dynamic sequence, $60 \times 5 \mathrm{~s}, 25 \times 60 \mathrm{~s}$, and each PET frame was reconstructed (Siemens e 7 tools) into a $172 \times 172 \times 127$ matrix using the ordinary Poisson ordered subset expectation maximization three-dimensional algorithm (3 iterations, 21 subsets, Gaussian filter). Scatter correction was performed with Dixon-based magnetic resonance-attenuation correction. 
Simultaneously acquired MRI consisted of a T1-weighted sequence with axial breath holding, fat suppression and spectrally adiabatic inversion recovery (VIBE SPAIR) and was used to accurately delineate kidneys and vessels.

For PET/MRI analysis, three volumes-of-interest (VOIs) were manually drawn in respective layers of the T1 MRI sequence using the Hermes Hybrid Viewer (Hermes Medical Solutions, Stockholm, Sweden): (1) descending aorta between the diaphragm and the renal arteries, (2) left kidney, and (3) right kidney. After delineation, the VOIs were copied to the PET images, from which the FDG time activity curves (TACs) were calculated in units of $\mathrm{kBq} / \mathrm{mL}$.

FDG TAC analysis was performed using an inhouse Javabased tool (programmed with OpenJDK V.1.8.0_162). The program was fed with the TACs of the kidneys as well as the aorta, which was also used as arterial input function (AIF). The mean of standardized uptake value (SUV) uptake between 2 and $3 \mathrm{~min}$ was additionally determined for each kidney by calculating the integral of the sum of the according TAC between 2 and 3 min after FDG injection. This cumulative uptake was considered as a measure for GRP and was previously used for determination of various kidney parameters. ${ }^{19-21}$

For the MTT that represents kidney excretion rate, the renal retention function of a corresponding TAC needed to be determined. ${ }^{22}$ The retention function was calculated from the AIF with a matrix deconvolution algorithm according to Kempi. ${ }^{23}$ In order to reduce noise and to smooth the curves, a Savitzky-Golay filter was applied on the TACs before deconvolution. ${ }^{24}$ The MTT was then calculated for each kidney by dividing the area under retention function by the height of the plateau. ${ }^{25}$

\section{Statistical analysis}

Statistical analysis was performed using Gnumeric (open-source software, V.1.12.20), LibreOffice Calculator (open-source software, V.6.0.3.2) and SPSS V.24.0. Kolmogorov-Smirnov test was used to determine distribution of the studied parameters. Not normally distributed data are presented as medians and ranges and were $\log _{10^{-}}$ transformed for all statistical analyses. Correlations have been calculated with Pearson product-moment correlation coefficient $r$, from which $\mathrm{p}$ values were derived. The significance of differences between values was determined with a paired Student's t-test, where $p<0.05$ was considered a statistically significant difference.

\section{RESULTS}

The demographical parameters of the healthy participants and of the 20 patients with T2DM (10 men, 10 women) at baseline are shown in table 1. In addition, clinical and laboratory parameters measured at baseline and 2 weeks after SGLT2i therapy are presented in table 2.

Change of renal parameters under SGLT2i therapy

While both GFR and creatinine levels of patients with T2DM showed no significant change during therapy,
Table 1 Demographics of the 20 studied patients with type 2 diabetes mellitus before starting SGLT2i therapies and the 24 healthy participants

\begin{tabular}{|c|c|c|}
\hline Parameters & $\begin{array}{l}\text { Patients with type } \\
2 \text { diabetes }(n=20)\end{array}$ & $\begin{array}{l}\text { Healthy } \\
\text { control } \\
(n=24)\end{array}$ \\
\hline Gender (\%) & $\begin{array}{l}50 \% \text { male, } 50 \% \\
\text { female }\end{array}$ & $\begin{array}{l}75 \% \text { male, } \\
25 \% \text { female }\end{array}$ \\
\hline Age (years), mean $\pm S D$ & $\begin{array}{l}65 \pm 10 \text { (range } \\
38-78)\end{array}$ & $\begin{array}{l}39 \pm 9 \text { (range } \\
21-65)\end{array}$ \\
\hline Weight $(\mathrm{kg})$, mean $\pm S D$ & $87 \pm 16$ & $85 \pm 18$ \\
\hline $\operatorname{BMI}\left(\mathrm{kg} / \mathrm{m}^{2}\right)$, mean $\pm S D$ & $31 \pm 5$ & $26 \pm 5$ \\
\hline $\begin{array}{l}\text { Baseline HbA1c, \% } \\
(\mathrm{mmol} / \mathrm{mol}), \text { mean } \pm \mathrm{SD}\end{array}$ & $\begin{array}{l}7.5(58) \pm 0.9, \text { range } \\
6.6(49)-9.8(84)\end{array}$ & n.a. \\
\hline $\begin{array}{l}\text { Duration of diabetes } \\
\text { (years), mean } \pm S D\end{array}$ & $12 \pm 8$ (range $1-30)$ & n.a. \\
\hline \multicolumn{2}{|c|}{ Concomitant antidiabetic medication, $\mathrm{n}(\%)$} & n.a. \\
\hline Only insulin & $3(15)$ & \\
\hline Insulin + OADs & $1(5)$ & \\
\hline Only OADs & $13(65)$ & \\
\hline No previous therapies & $3(15)$ & \\
\hline \multicolumn{2}{|c|}{ Cardiovascular diseases, n (\%) } & n.a. \\
\hline $\mathrm{CHD}$ & $4(20)$ & \\
\hline HTN & $18(90)$ & \\
\hline On RAAS inhibitors & $12(60)$ & \\
\hline No RAAS inhibitors & $8(40)$ & \\
\hline Hyperlipidemia, n (\%) & $19(95)$ & n.a. \\
\hline \multicolumn{3}{|l|}{ Smoking status, n (\%) } \\
\hline Never & $9(45)$ & $13(54.2)$ \\
\hline Former & $8(40)$ & $4(16.6)$ \\
\hline Current & $3(15)$ & $7(29.2)$ \\
\hline
\end{tabular}

$\mathrm{BMI}$, body mass index; CHD, coronary artery disease; HbA1c, glycated hemoglobin; HTN, arterial hypertension; n.a., not applicable; OADs, oral antidiabetic drugs; RAAS, reninangiotensin-aldosterone system inhibitors; SGLT2i, sodiumglucose linked transporter-2 inhibitor.

GFR values at $\mathrm{T}_{2} \mathrm{DM}_{\text {baseline }}$ and $\mathrm{T} 2 \mathrm{DM}_{\mathrm{SGLT2i}}$ were significantly lower as compared with healthy controls (92 and 86 vs $122 \mathrm{~mL} / \mathrm{min} / 1.73 \mathrm{~m}^{2}$, respectively, both $\mathrm{p}<0.001$; table 3). The MTT in patients with T2DM at baseline was significantly higher than in healthy controls $(5.7 \mathrm{~min}$ vs $4.3 \mathrm{~min}, \mathrm{p}=0.012$ ), but significantly decreased from $5.7 \mathrm{~min}$ at baseline to $4.4 \mathrm{~min}$ after 2 weeks of therapy ( $\mathrm{p}=0.004$; figure $1 \mathrm{~A}$, table 3 ).

Similarly, the GRP in patients with T2DM at baseline was markedly lower when compared with healthy individuals (4.7 $\mathrm{min}$ vs $5.1 \mathrm{~min}$ ), but did not reach statistical significance $(\mathrm{p}=0.06)$. Two weeks after SGLT2i treatment, GRP significantly increased from 4.7 to $5.2(\mathrm{p}=0.02)$ to a similar range as in healthy controls $(5.1 \mathrm{~min})$ (figure $1 \mathrm{~B}$, table 2). 
Table 2 Clinical and laboratory parameters of the 20 patients with type 2 diabetes (10 male, 10 female), measured at baseline and 2 weeks after receiving SGLT2i therapies

\begin{tabular}{|c|c|c|c|}
\hline Parameters (mean $\pm S D)$ & T2DM $_{\text {baseline }}$ & T2DM $_{\text {SGLT2i }}$ & $P$ value \\
\hline Weight (kg) & $87.45 \pm 16$ & $87.25 \pm 16$ & NS \\
\hline \multicolumn{4}{|l|}{ Blood pressure (mm Hg) } \\
\hline Systolic & $134 \pm 12$ & $131 \pm 13$ & NS \\
\hline Diastolic & $77 \pm 11$ & $77 \pm 9$ & NS \\
\hline $\mathrm{HbA} 1 \mathrm{c}, \%(\mathrm{mmol} / \mathrm{mol})^{*}$ & $7.45(58) \pm 0.87$ & $6.95(52) \pm 0.63$ & 0.006 \\
\hline Glucose (mg/dL) & $158 \pm 43$ & $138 \pm 34$ & 0.01 \\
\hline Hematocrit (\%) & $41.6 \pm 2.8$ & $41.7 \pm 3.1$ & NS \\
\hline Erythrocyte (T/L) & $4.7 \pm 0.35$ & $4.7 \pm 0.38$ & NS \\
\hline Thrombocyte (G/L) & $235 \pm 56$ & $236 \pm 53$ & NS \\
\hline Uric acid (mg/dL) & $5.1 \pm 1.2$ & $4.6 \pm 1.0$ & 0.057 \\
\hline Bilirubin (mg/dL) & $0.56 \pm 0.3$ & $0.62 \pm 0.29$ & 0.02 \\
\hline ALP (U/L) & $65 \pm 18$ & $62 \pm 17$ & 0.04 \\
\hline ASAT (U/L) & $24 \pm 6$ & $23 \pm 4$ & NS \\
\hline ALAT (U/L) & $27 \pm 10$ & $27 \pm 8$ & NS \\
\hline Gama GT (U/L) & $29 \pm 19$ & $27 \pm 15$ & NS \\
\hline Creatine kinase $(U / L)$ & $115 \pm 43$ & $104 \pm 25$ & NS \\
\hline CRP (mg/dL)† & $0.38(0.02-1.38)$ & $0.31(0.02-1.15)$ & NS \\
\hline Total cholesterol (mg/dL) & $169 \pm 48$ & $148 \pm 34$ & 0.05 \\
\hline LDL (mg/dL) & $86 \pm 33$ & $79 \pm 25$ & NS \\
\hline $\mathrm{HDL}(\mathrm{mg} / \mathrm{dL})$ & $52 \pm 14$ & $50 \pm 13$ & NS \\
\hline Triglyceride (mg/dL) & $158 \pm 92$ & $139 \pm 43$ & NS \\
\hline
\end{tabular}

${ }^{*}$ Compared with values 3 months after receiving SGLT2i therapies.

†Data not normally distributed, $\log _{10}$ transferred for analysis and presented as mean (range).

ALAT, alanine aminotransferase; ALP, leukocyte phosphatase; ASAT, aspartate aminotransferase; CRP, C-reactive protein; Gamma GT, gamma-glutamyl transferase; HbA1c, glycated hemoglobin; HDL, high density lipoprotein cholesterol; LDL, low density lipoprotein cholesterol; NS, not significant; SGLT2i, sodium-glucose linked transporter-2 inhibitor; T2DM, type 2 diabetes mellitus.

\section{Prediction of response to SGLT2i therapy}

HbAlc levels decreased from $7.5 \%(58 \mathrm{mmol} / \mathrm{mol}) \pm 0.9$ at baseline to $6.9 \%(52 \mathrm{mmol} / \mathrm{mol}) \pm 0.6$ after 3 months of SGLT2i therapy $(\mathrm{p}<0.001)$. Out of 20 patients, $16(80 \%)$ with T2DM showed documented treatment response, and $4(20 \%)$ patients showed no change or increase in HbAlc levels and were rated as non-responder.
A significant negative correlation $(\mathrm{r}=-0.6, \mathrm{p}=0.005)$ was found between the baseline $\mathrm{HbAlc}$ values and the reduction of HbAlc after 3 months of therapy. Moreover, nonresponders had a significantly higher weight of $110 \pm 5 \mathrm{~kg}$ at baseline as compared with responders $(82 \pm 12 \mathrm{~kg}$, $\mathrm{p}<0.001)$.

Table 3 Measured non-imaging and imaging renal functional parameters in healthy subjects as well as in T2DM baseline $_{\text {and }}$ $\mathrm{T}_{2 \mathrm{DM}}$ SGLT2

\begin{tabular}{lllll}
\hline $\begin{array}{l}\text { Renal parameters } \\
\text { (mean } \pm \text { SD) }\end{array}$ & Healthy individuals & T2DM $_{\text {baseline }}$ & T2DM $_{\text {SGLT2i }}$ & P value \\
\cline { 3 - 5 } & $0.9 \pm 0.16$ & $0.9 \pm 0.21$ & $0.95 \pm 0.23$ & $\mathrm{NS}$ \\
\hline Creatinine $(\mathrm{mg} / \mathrm{dL})$ & $122 \pm 21^{*} \dagger$ & $92 \pm 22^{*}$ & $86 \pm 24 \dagger$ & $0.001^{*} \dagger$ \\
GFR $\left(\mathrm{mL} / \mathrm{min} / 1.73 \mathrm{~m}^{2}\right)$ & $4.3 \pm 1.8^{*}$ & $5.7 \pm 3.0^{*} \ddagger$ & $4.4 \pm 2.2 \ddagger$ & $0.012^{*}, 0.004 \ddagger$ \\
MTT $(\mathrm{min})$ & $5.1 \pm 1.1$ & $4.7 \pm 1.0 \ddagger$ & $5.2 \pm 0.8 \ddagger$ & $0.02 \ddagger$
\end{tabular}

${ }^{*}$ Significant differences between healthy subjects and T2DM ${ }_{\text {baseline. }}$.

†Significant differences between healthy subjects and T2DM $\mathrm{Baseline}_{\mathrm{SG} \text {. }}$.

\#Significant differences between T2DM $\mathrm{baseline}$ and T2DM $\mathrm{SGLT2}^{*}$

GFR, glomerular filtration rate; GRP, general renal performance; MTT, mean transit time; NS, not significant; SGLT2i, sodium-glucose linked transporter-2 inhibitor; T2DM, type 2 diabetes mellitus. 

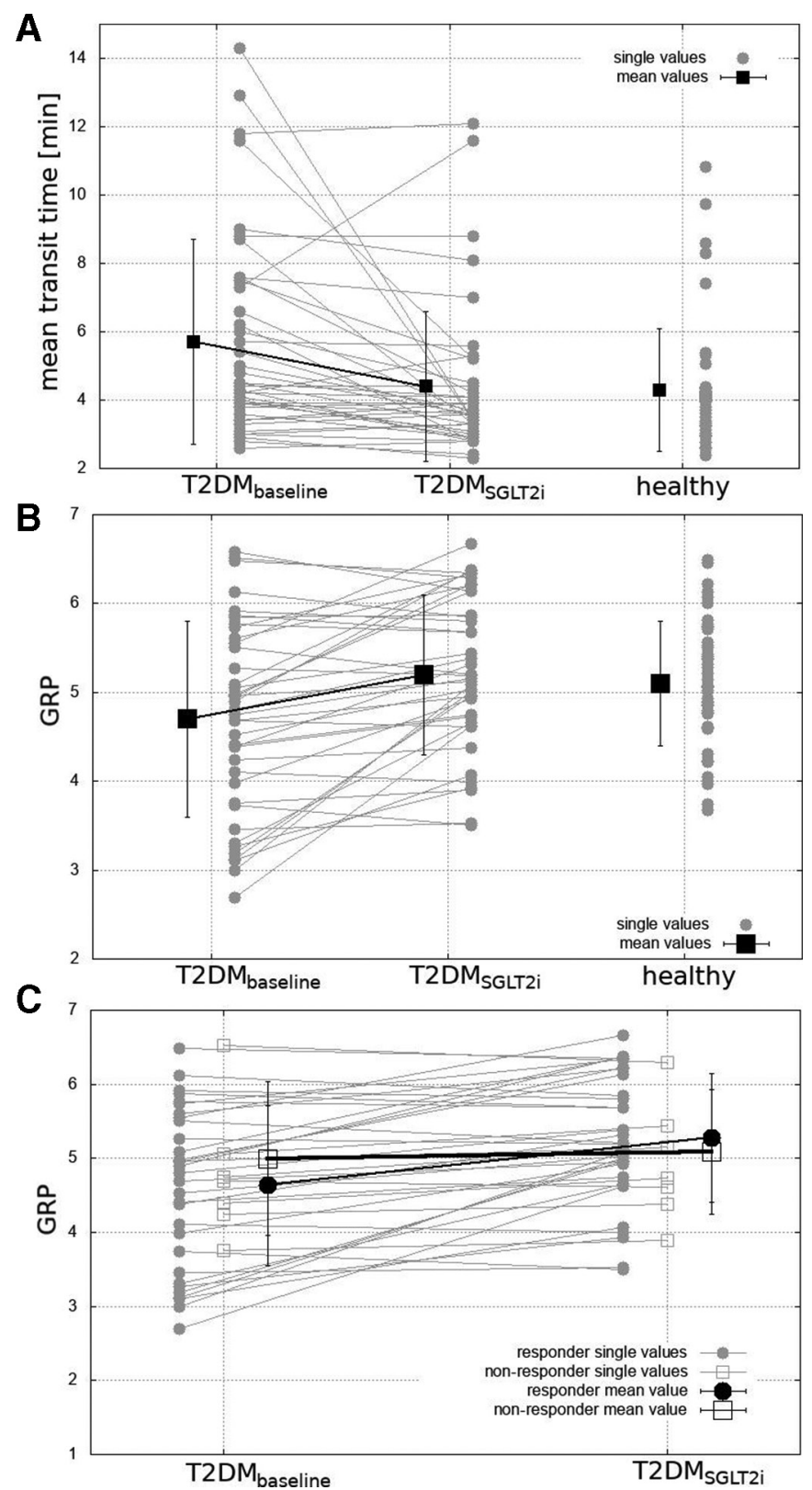

Figure 1 (A) Mean transit times of T2DM $\mathrm{Maseline}_{\text {and }}$ $\mathrm{T} 2 \mathrm{DM}_{\mathrm{SGLT2 \textrm {i }}}$ versus healthy controls. Mean transit times at baseline were significantly higher than in healthy controls ( $5.7 \mathrm{~min}$ vs $4.3 \mathrm{~min}, \mathrm{p}=0.012$ ) and significantly higher than in 2 weeks after initiation of therapy (5.7 min vs $4.4 \mathrm{~min}$, $\mathrm{p}=0.004)$. (B) GRP in T2DM $\mathrm{baseline}_{\text {and T2DM }}$ aGLT2i versus healthy controls. In comparison with healthy controls, $\mathrm{T}^{2} \mathrm{DM}_{\text {baseline }}$ revealed lower levels of GRP $(5.1 \mathrm{~min}$ vs $4.7 \mathrm{~min}$, $p=0.06)$. Two weeks after SGLT2i treatment, GRP increased from 4.7 to $5.2(p=0.02)$ and was almost equal to healthy volunteers. (C) GRP in T2DM baseline $_{\text {and T2DM }}$ aGLT2i in relation to response to SGLT2i therapy. In case of responders to SGLT2i therapy, significant increase in GRP $(p<0.01)$ was observed from baseline to 2 weeks after initiation of therapy (circles). No relevant changes $(p=0.46)$ in GRP values among non-responder patients before and after initiation of to SGLT2i therapy were found (squares). GRP, general renal performance; SGLT2i, sodium-glucose linked transporter-2 inhibitor; T2DM, type 2 diabetes mellitus.
Regarding FDG parameters, although MTT at baseline and 2 weeks after initiation of therapy with SGLT2i was not significantly different between therapy responder and therapy non-responder patients with T2DM, GRP among responders was significantly higher after therapy as compared with baseline ( 5.3 vs $4.6, \mathrm{p}<0.01$ ). However, no linear correlation was found between $\mathrm{HbAlc}$ reduction and GRP increase in the responder group $(\mathrm{r}=-0.21)$. Also, no relevant changes in GRP values were observed among non-responder patients before and 3 months after initiation of therapy with SGLT2i (5.1 vs 5.0, $\mathrm{p}=0.47$ ) (figure 1C).

Interestingly, levels of serum uric acid at baseline were inversely correlated with GRP in responders $(r=-0.84$, $\mathrm{p}<0.001)$, while there was no significant correlation found in non-responders $(\mathrm{r}=-0.58, \mathrm{p}=0.42)$.

\section{DISCUSSION}

It is well known that kidneys play an important role in glucose homeostasis in both diabetic and non-diabetic conditions. SGLT2i therapies by preventing glucose input into the renal tubular cells protect kidneys from the deleterious effects of hyperglycemia among patients with T2DM. ${ }^{26}$

One of the main objectives of the current study was to investigate the effects of SGLT2i treatment on renal parameters in patients with T2DM receiving daily therapy for 2 weeks. In addition to routinely known standard renal parameters, dynamic FDG PET/MRI was used to provide in vivo renal function including SGLT2 transporter function, as FDG to a minor extent is used via SGLT2 and might therefore change its ordinary behavior in kidneys after obtaining SGLT2i. We primarily focused on the level of MTT, which is a surrogate marker to presage the kidney excretion rate, and on the level of kidney FDG uptake that represents FDG accumulation in renal parenchymal tissue and an important measure of GRP for kidney functionality.

As we compared FDG renal imaging parameters of the healthy subjects with that of patients with T2DM prior to receiving SGLT2i therapies, we found that the kidney tracer excretion rate in terms of MTT in healthy subjects was significantly lower than in $\mathrm{T}_{2} \mathrm{DM}_{\text {baseline }}$, while FDG renal accumulation by means of GRP in the healthy cohort was significantly higher than of $\mathrm{T}_{2} \mathrm{DM}_{\text {baseline}}$. Indeed, hyperglycemia impairs renal function, and therefore subjects with diabetes are at considerably higher risk of developing different degrees of renal diseases and have poorer renal function than individuals with no diabetes. About $40 \%$ of patients with diabetes will develop some degree of diabetic nephropathy in the course of the disease. ${ }^{27}$ Nevertheless, after only 2 weeks of SGLT2i therapies, the levels of MTT and GRP reached similar ranges as compared with healthy controls, which indicates FDG reactivity to SGLT2i. Reduction of FDG reabsorption under the influence of SGLT2i might induce availability of more FDG (1) for excretion, thus the 
MTT of T2DM ${ }_{\text {SGLT2i }}$ is lower compared with T2DM $_{\text {baseline; }}$; and (2) for accumulation, thus GRP is higher in healthy controls and in $\mathrm{T}_{2} \mathrm{DM}_{\mathrm{SGLT2i}}$ than in $\mathrm{T}_{2} \mathrm{DM}_{\text {baseline }}$. Accordingly, the results of the study showed that levels of MTT are lower and levels of GRP are higher in $\mathrm{T}_{2} \mathrm{DM}_{\mathrm{SGLT2i}}$ than in $\mathrm{T}_{2} \mathrm{DM}_{\text {baseline }}$. Our observation of about $10 \%$ increase of GRP due to the inhibited FDG reabsorption is in good agreement with previous publications. ${ }^{1}$

Moreover, among patients with diabetes, the results demonstrated, very interestingly, a significant decline in levels of MTT (ie, outflow or excretion efficacy) in $\mathrm{T}_{2} \mathrm{DM}_{\mathrm{SGLT2 \textrm {i }}}$ comparing with $\mathrm{T}_{2} \mathrm{DM}_{\text {baseline }}$. Two weeks after initiation of therapy with gliflozins, GRP as a surrogate marker of kidney functionality increased significantly in $\mathrm{T}_{2} \mathrm{DM}_{\mathrm{SGLT2i}}$ in comparison with $\mathrm{T}_{2} \mathrm{DM}_{\text {baseline }}$. Interestingly, among the responders to SGLT2i therapy, values of GRP were significantly higher after therapy as compared with baseline; thus, GRP only 2 weeks after the therapy was significantly higher than the baseline if HbAlc was reduced 3 months after initiation of therapy with SGLT2i.

We previously demonstrated the feasibility and validity of kidney functional parameters such as split function, MTT, GFR and effective renal plasma flow as determined with dynamic FDG PET/MRI. Likewise, with the help of high-resolution MRI sequences, we could exactly delineate morphological structures to monitor the FDG concentration over time. ${ }^{15}$ Consequently, our study highlights and confirms the nephroprotective effects of SGLT2i therapies among patients with T2DM. Matching these results, in vivo and in vitro studies indicated that SGLT2i lowers glomerular hyperfiltration and diminishes tubulointerstitial inflammation and fibrosis that are induced by the elevated glucose in the tubular cells of patients with diabetes. ${ }^{28} 29$

Regarding non-imaging renal parameters, although levels of serum creatinine did not differ significantly between the healthy cohort and the patients with T2DM, the results revealed that the studied patients with T2DM, $90 \%$ of whom suffered from high blood pressure at the same time (as shown in table 1), had a significantly lower GFR than healthy controls. Notably, levels of GFR among the cohort with diabetes further declined 2 weeks after starting SGLT2i therapies. This observation is compatible with the results of previous studies which revealed an early, short-term, and reversible reduction in GFR a few weeks after initiation of SGLT2i therapies that spontaneously revised with the continuation of treatment. ${ }^{30}$

\section{Limitation of the study}

Since the study was a proof of concept to show the impact of SGLT2i on the FDG renal function parameters, it did not include another comparator arm with other antidiabetic therapies. In addition, the small sample size of patients with T2DM recruited for this clinical trial may limit the results of this study. Hence, we currently lack the plausible reasons behind the relation of GRP to HbAlc observed among the participants and we strive to clarify it within the frame of our planned future studies.

\section{CONCLUSIONS}

SGLT2 $i$ therapies induced a significant improvement in kidney function of patients with T2DM as indicated by reduced MTT and improved GRP already 2 weeks after initiation of the therapy. Moreover, early increase of GRP was associated with long-term glycemic response to SGLT2i therapies.

\section{Author affiliations}

${ }^{1}$ Division of Nuclear Medicine, Medical University of Vienna, Vienna, Austria ${ }^{2}$ Diabetes \& Metabolic Outpatient Clinic, Health Centre Vienna South, Vienna, Austria

${ }^{3}$ Department of Biomedical Imaging and Image-guided Therapy, Division of General and Pediatric Radiology, Medical University of Vienna, Vienna, Austria

${ }^{4}$ Center for Medical Physics and Biomedical Engineering, Medical University of Vienna, Vienna, Austria

${ }^{5}$ Ludwig Boltzmann Institute Applied Diagnostics, Vienna, Austria

${ }^{6}$ Department of Internal Medicine III, Division of Endocrinology and Metabolism, Gender Medicine Unit, Medical University of Vienna, Vienna, Austria

Contributors SR wrote the manuscript, researched the data, contributed to discussion. BKG researched and analyzed the data, contributed to discussion. HB researched the data, contributed to discussion. PB and LKSS researched the data. VP and MM reviewed the manuscript. AK-W designed the study, contributed to discussion, reviewed the manuscript. MH wrote the manuscript, designed the study, contributed to discussion, reviewed/edited the manuscript.

Funding The authors have not declared a specific grant for this research from any funding agency in the public, commercial or not-for-profit sectors.

Competing interests None declared.

Patient consent for publication Not required.

Ethics approval The local institutional ethics committee of Medical University of Vienna has approved the study (EK: 1128/2016).

Provenance and peer review Not commissioned; externally peer reviewed.

Data availability statement Data are available upon reasonable request after passing a legal transaction form by the university.

Open access This is an open access article distributed in accordance with the Creative Commons Attribution Non Commercial (CC BY-NC 4.0) license, which permits others to distribute, remix, adapt, build upon this work non-commercially, and license their derivative works on different terms, provided the original work is properly cited, appropriate credit is given, any changes made indicated, and the use is non-commercial. See: http://creativecommons.org/licenses/by-nc/4.0/.

\section{ORCID iD}

Barbara Katharina Geist http://orcid.org/0000-0003-0098-0048

\section{REFERENCES}

1 Sala-Rabanal M, Hirayama BA, Ghezzi C, et al. Revisiting the physiological roles of SGLTs and GLUTs using positron emission tomography in mice. J Physiol 2016;594:4425-38.

2 Wright EM, Loo DDF, Hirayama BA. Biology of human sodium glucose transporters. Physiol Rev 2011;91:733-94.

3 Rahmoune H, Thompson PW, Ward JM, et al. Glucose transporters in human renal proximal tubular cells isolated from the urine of patients with non-insulin-dependent diabetes. Diabetes 2005;54:3427-34.

4 Thomas L, Grempler R, Eckhardt M, et al. Long-Term treatment with empagliflozin, a novel, potent and selective SGLT-2 inhibitor, improves glycaemic control and features of metabolic syndrome in diabetic rats. Diabetes Obes Metab 2012;14:94-6.

5 Cefalu WT, Leiter LA, Yoon K-H, et al. Efficacy and safety of canagliflozin versus glimepiride in patients with type 2 diabetes inadequately controlled with metformin (CANTATA-SU): 52 week results from a randomised, double-blind, phase 3 non-inferiority trial. Lancet 2013;382:941-50.

6 Ferrannini E, Ramos SJ, Salsali A, et al. Dapagliflozin monotherapy in type 2 diabetic patients with inadequate glycemic control by diet and exercise: a randomized, double-blind, placebo-controlled, phase 3 trial. Diabetes Care 2010;33:2217-24. 
7 Devineni D, Morrow L, Hompesch M, et al. Canagliflozin improves glycaemic control over 28 days in subjects with type 2 diabetes not optimally controlled on insulin. Diabetes Obes Metab 2012;14:539-45.

8 Rosenstock J, Vico M, Wei L, et al. Effects of dapagliflozin, an SGLT2 inhibitor, on $\mathrm{HbA}(1 \mathrm{c})$, body weight, and hypoglycemia risk in patients with type 2 diabetes inadequately controlled on pioglitazone monotherapy. Diabetes Care 2012;35:1473-8.

9 Barnett AH, Mithal A, Manassie J, et al. Efficacy and safety of empagliflozin added to existing antidiabetes treatment in patients with type 2 diabetes and chronic kidney disease: a randomised, double-blind, placebo-controlled trial. Lancet Diabetes Endocrinol 2014;2:369-84.

10 Yale J-F, Bakris G, Cariou B, et al. Efficacy and safety of canagliflozin in subjects with type 2 diabetes and chronic kidney disease. Diabetes Obes Metab 2013;15:463-73.

11 Perkovic V, Jardine MJ, Neal B, et al. Canagliflozin and renal outcomes in type 2 diabetes and nephropathy. $N$ Engl $J$ Med Overseas Ed 2019;380:2295-306.

12 Qiao H, Bai J, Chen Y, et al. Kidney modelling for FDG excretion with PET. Int J Biomed Imaging 2007;2007:63234.

13 Szabo Z, Xia J, Mathews WB, et al. Future direction of renal positron emission tomography. Semin Nucl Med 2006;36:36-50.

14 Kobayashi M, Shikano N, Nishii R, et al. Comparison of the transcellular transport of FDG and D-glucose by the kidney epithelial cell line, LLC-PK1. Nucl Med Commun 2010;31:141-6.

15 Geist BK, Baltzer P, Fueger B, et al. Assessing the kidney function parameters glomerular filtration rate and effective renal plasma flow with dynamic FDG-PET/MRI in healthy subjects. EJNMMI Res 2018;8:37.

16 Fleming JS, Kemp PM. A comparison of deconvolution and the Patlak-Rutland plot in renography analysis. J Nucl Med 1999;40:469-7.

17 Gates GF. Split renal function testing using Tc-99m DTPA. A rapid technique for determining differential glomerular filtration. Clin Nucl Med 1983;8:400-7.
18 American Diabetes Association. 9. Pharmacologic Approaches to Glycemic Treatment: Standards of Medical Care in Diabetes-2019. Diabetes Care 2019;42:S90-102.

19 Wesolowski MJ, Conrad GR, Šámal M, et al. A simple method for determining split renal function from dynamic (99m)Tc-MAG3 scintigraphic data. Eur J Nucl Med Mol Imaging 2016;43:550-8.

20 Ortapamuk H, Naldoken S, Tekdogan UY, et al. Differential renal function in the prediction of recovery in adult obstructed kidneys after pyeloplasty. Ann Nucl Med 2003;17:663-8.

21 Gates GF. Glomerular filtration rate: estimation from fractional renal accumulation of 99mTc-DTPA (stannous). AJR Am J Roentgenol 1982;138:565-70.

22 Durand E, Blaufox MD, Britton KE, et al. International scientific Committee of radionuclides in Nephrourology (ISCORN) consensus on renal transit time measurements. Semin Nucl Med 2008;38:82-102.

23 Kempi V. A FORTRAN program for deconvolution analysis using the matrix algorithm method with special reference to renography. Comput Methods Programs Biomed 1987;24:107-16.

24 Savitzky A, Golay MJE. Smoothing and differentiation of data by simplified least squares procedures. Anal Chem 1964;36:1627-39.

25 Fleming JS. Functional radionuclide imaging of renal mean transit time and glomerular filtration rate. Nucl Med Commun 1988;9:85-96.

26 Andrianesis V, Glykofridi S, Doupis J. The renal effects of SGLT2 inhibitors and a mini-review of the literature. Ther Adv Endocrinol Metab 2016;7:212-28.

27 American Diabetes Association. Standards of medical care in diabetes--2014. Diabetes Care 2014;37 Suppl 1:S14-80.

28 Vallon V, Gerasimova M, Rose MA, et al. Sglt2 inhibitor empagliflozin reduces renal growth and albuminuria in proportion to hyperglycemia and prevents glomerular hyperfiltration in diabetic Akita mice. Am J Physiol Renal Physiol 2014;306:F194-204.

29 Panchapakesan U, Pegg K, Gross S, et al. Effects of SGLT2 inhibition in human kidney proximal tubular cells--renoprotection in diabetic nephropathy? PLoS One 2013;8:e54442.

30 Kelly MS, Lewis J, Huntsberry AM, et al. Efficacy and renal outcomes of SGLT2 inhibitors in patients with type 2 diabetes and chronic kidney disease. Postgrad Med 2019;131:31-42. 